\title{
Rock phosphate solubilisation by strains of Penicillium spp. isolated from farm and forest soils of three agro ecological zones of Cameroon
}

\author{
Fankem Henri $^{1,}$,, Ngo Nkot Laurette ${ }^{1}$, Nguesseu Njanjouo Ghislain ${ }^{1}$, \\ Tchuisseu Tchakounte Gylaine Vanessa ${ }^{1}$, Tchiazé Ifoué Alice Virginie ${ }^{1}$, Nwaga Dieudonné2 \\ ${ }^{1}$ Department of Plant Biology, Faculty of Science, University of Douala, Douala, Cameroon \\ ${ }^{2}$ Department of Plant Biology and Physiology, Faculty of Science, University of Yaoundé I, Yaoundé, Cameroon
}

\section{Email address:}

fankemhenri@yahoo.fr (H. Fankem)

\section{To site this article:}

Fankem Henri, Ngo Nkot Laurette, Nguesseu Njanjouo Ghislain, Tchuisseu Tchakounte Gylaine Vanessa, Tchiazé Ifoué Alice Virginie, Nwaga Dieudonné. Rock Phosphate Solubilisation by Strains of Penicillium Spp. Isolated from Farm and Forest Soils of three Agro Ecological Zones of Cameroon. American Journal of Agriculture and Forestry. Vol. 2, No. 2, 2014, pp. 25-32.

doi: 10.11648/j.ajaf.20140202.12

\begin{abstract}
Rock Phosphate (RP) is theoretically the cheapest fertilizer and most abundant, but its direct application in the soils is not always agronomically effective due to its low phosphorus (P) availability. An environmentally friendly and economically alternative to traditional processing of these deposits is the use of Phosphate Solubilising Microorganisms (PSM). Three Penicillium strains were screened for their aptitude in solubilising sparingly soluble phosphates as well as phosphate rock on plates and in broth supplemented with the different phosphate types. The three strains show the ability in solubilising at least two from the sparingly soluble phosphates types, with the solubilisation index (SI) varying from 1.44 to 4.74. All the strains were able to show halo zone on plates supplemented with Malian and Algerian rock phosphates with solubilisation index ranging from 1.2 to 1.8. No halo zone was detected on plates with Moroccan rock phosphate as sole phosphate source. However, significant amount of phosphorus were mobilised by all strains in broth with the different rock phosphates, including the Moroccan rock phosphate. The amount of solved P varied from $257.46 \mathrm{mgP.L}^{-1}$ (Penicillium sp. 43) to $326.65 \mathrm{mgP.L} \mathrm{L}^{-1}$ (Penicillium sp. 109) for Malian rock phosphate, from $152.61 \mathrm{mgP.L} \mathrm{L}^{-1}$ (Penicillium sp. 43) to 337.56 mgP.L ${ }^{-1}$ (Penicillium sp. 27) for Algerian rock phosphate, and from 283.79 mgP.L (Penicillium sp. 43 ) to 347.16 mgP.L $^{-1}$ (Penicillium sp. 109) for Moroccan rock phosphate. The rock phosphate solubilisation was associated with $\mathrm{pH}$ media drop and both parameters were strongly correlated.
\end{abstract}

Keywords: Penicillium Spp, Rock Phosphates, Fixed Phosphates, Phosphate Solubilisation

\section{Introduction}

The optimal development of crops demands a high, often costly input of $\mathrm{P}$ fertilizers. Current concepts in sustainability involve application of alternative strategies based on the use of less expensive natural sources of plant nutrients like rock phosphate. The beneficial effect of rock phosphate has made this material an attractive component for management in agriculture [1]. However, the direct application of low-grade rock phosphate as a $\mathrm{P}$ source in neutral and alkaline soils was of little importance [2,3]. In Mali, the use of Tilemsi Rock Phosphate (TPR) as phosphorus source was limited by its inefficiency in many agricultural soils [4]. However, Addition of an inoculum of phosphate solubilising microorganisms to soil has also been found to improve the rock phosphate efficiency as a phosphorus source [5]. Many soil microorganisms, including bacteria and fungi, are able to mobilize phosphorus from sparingly soluble rock phosphates, and they have an enormous potential in providing soil phosphates for plant growth [6,7]. Microbial solubilisation of rock phosphate, especially low grade and its use in agriculture is receiving greater attention. This process not only compensates for higher cost of manufacturing fertilizers in industry but also mobilises the fertilizers added to soil [8]. The present study aims at characterizing the rock phosphate solubilising ability of three Penicillium strains isolated from different agro ecological zones of Cameroon. 


\section{Materials and Methods}

\subsection{Sampling Zones Description}

The three fungi strains were obtained from soils collected in three out of the five agro ecological zones of Cameroon: The High Guinea Savanna Zone II, the southern plateau raises northward to the grassy, rugged Adamawa Plateau. This feature stretches from the western mountain area and forms a barrier between the country's north and south. Its average elevation is 1,100 meters and its temperature ranges from $22{ }^{\circ} \mathrm{C}$ to $25^{\circ} \mathrm{C}$ with high rainfall. The Western Highlands Zone III, an irregular chain of mountains, hills, and plateaus known as the Cameroon range extends from Mount Cameroon on the coast (Cameroon's highest point at 4,095 meters) almost to Lake Chad at Cameroon's northern tip. This region has a mild climate, particularly on the Western High Plateau, although rainfall is high. Its soils are among Cameroon's most fertile, especially around volcanic Mount Cameroon. This area has been delineated by the World Wildlife Fund as the Cameroonian Highlands forests ecoregion. The Bimodal Humid Forest Zone V, the South Cameroon Plateau rises from the coastal plain to an average elevation of 650 meters. Equatorial rainforest dominates this region, although its alternation between wet and dry seasons makes it less humid than the coast. This area is part of the Atlantic Equatorial coastal forests ecoregion. In general, the climate varies with terrain, from tropical along the coast to semiarid and hot in the north. Exceedingly hot and humid, the coastal belt includes some of the wettest places on earth. Top soils $(0-25 \mathrm{~cm}$ depth) were collected from forest and farmed locations of these agro ecological zones for strains isolation and characterization.

\subsection{Isolation and Characterization of Strains on Plates Supplemented with Sparingly Soluble Phosphates}

Rock-phosphate-solubilising fungi were isolated from farm and forest soils collected in three agro ecological zones of Cameroon using the dilution plate method. Ten grams (10) soil sample were mixed with $90 \mathrm{ml}$ sterile distilled water, vigorously shacked and left to stand for 5 minutes. Series of the homogeneous soil was diluted and the $10^{-5}-10^{-6}$ dilutions plated on non selective LB medium (10 g Peptone, $5 \mathrm{~g}$ Yeast, $10 \mathrm{~g} \mathrm{NaCl}, 15 \mathrm{~g}$ Agar, $1000 \mathrm{ml}$ Distilled water, $\mathrm{pH}$ 7.5) used for broad spectrum microorganisms. Fungi were purified by several transfers of fungal mycelia into new media until obtaining the pure fungal culture. Fungi strains were maintained on LB agar slants until use.

To assess the phosphate solubilisation activity of microorganisms, pure fungal colonies were individually suspended into $10 \mathrm{ml} \mathrm{LB}$ broth and incubated at $28{ }^{\circ} \mathrm{C}, 150$ rpm, for 5 days. Ten microliters of each fungal suspension were transferred onto a single point of Petri dish containing P-free minimal medium (MM) containing per liter distilled water; $0.4 \mathrm{~g} \mathrm{NH}_{4} \mathrm{Cl}, 0.78 \mathrm{~g} \mathrm{KNO}_{3}, 0.1 \mathrm{~g} \mathrm{NaCl}, 0.25 \mathrm{~g} \mathrm{MgSO}_{4}$ $0.1 \mathrm{~g} \mathrm{CaCl}_{2} \cdot 2 \mathrm{H}_{2} \mathrm{O}, 0.27 \mathrm{mg} \mathrm{FeSO}_{4}, 1.56 \mathrm{mg} \mathrm{MnSO}_{4} \cdot \mathrm{H}_{2} \mathrm{O}$, $1.40 \mathrm{mg} \mathrm{ZnSO} 4 \cdot 7 \mathrm{H} 2 \mathrm{O}, 10 \mathrm{~g}$ Glucose, $20 \mathrm{~g}$ Agar, and one of the four insoluble phosphate types (either $\mathrm{Ca}_{3}\left(\mathrm{PO}_{4}\right)_{2}$ (Ca-P) or $\mathrm{AlPO}_{4}(\mathrm{Al}-\mathrm{P})$, or $\mathrm{FePO}_{4}(\mathrm{Fe}-\mathrm{P})$, or Na-Phytate (Na-phy)) at $30 \mathrm{mM} \mathrm{P}$, plus $0.5 \% \mathrm{BCG}$ (Bromocresol green) dye [9] for better observation. A stock solution of $0.5 \%$ dye was prepared by dissolving a corresponding weight of Bromocresol green into $70 \%$ ethanol and the final $\mathrm{pH}$ adjusted to 6.5 with $\mathrm{KOH} 1 \mathrm{M}$. The plates were sealed and incubated at $28{ }^{\circ} \mathrm{C}$ for 5 days and the phosphate solubilisation recorded through the halo/yellow zone surrounding the fungal colony. The index of solubilisation (IS) as defined by Qureshi et al. [10] was used as an indicator for the isolate efficiency:

IS $=($ Colony diameter + diameter of halo zone $) /$ Colony diameter.

\subsection{Characterization of Strains on Plates Supplemented with Rock Phosphate from Different Origins}

Three rock phosphates of different origins with characteristics indicated in Table 1 were used. To remove the soluble fraction, the different rock phosphates were washed four times with worm distilled water according to the cycle: 1 hour -24 hours - 1 hour -24 hours. They were then completely dried in oven at $60{ }^{\circ} \mathrm{C}$ and homogenised before use.

Table 1. Mineral composition of the different rock phosphates used. (Magallón-Servin, unpublished).

\begin{tabular}{ccccccccccccc}
\hline Origin & & \multicolumn{1}{c}{ Mineral elements (\%) } & \multicolumn{4}{c}{$\mathbf{m g} / \mathbf{k g}$} \\
Rock P & Total $\mathbf{P}_{\mathbf{2}} \mathbf{O}_{\mathbf{5}}$ & Available & $\mathbf{P}$ & $\mathbf{K}$ & $\mathbf{C a}$ & $\mathbf{M g}$ & $\mathbf{N a}$ & $\mathbf{F e}$ & $\mathbf{A l}$ & $\mathbf{M n}$ & $\mathbf{Z n}$ & $\mathbf{C u}$ \\
\hline Mali & 30 & 12.98 & 0.056 & 28.19 & 0.131 & 0.232 & 3.844 & 0.80 & 8360 & 87 & 51 \\
Morocco & 13 & 9.33 & 0.093 & 28.83 & 1.93 & 0.552 & 0.267 & 0.42 & 96 & 219 & 38 \\
Algeria & 29 & $\mathrm{Nd}$ & $\mathrm{Nd}$ & $\mathrm{Nd}$ & $\mathrm{Nd}$ & $\mathrm{Nd}$ & $\mathrm{Nd}$ & $\mathrm{Nd}$ & $\mathrm{Nd}$ & $\mathrm{Nd}$ & $\mathrm{Nd}$ \\
\hline
\end{tabular}

Nd : Not determined.

The characterisation of strains for their rock phosphate solubilising ability was assessed as previously described but the medium used was the National Botanical Research Institute's Phosphate growth medium (NBRIP) [11] with some modifications and containing per liter of distilled water: glucose, $20 \mathrm{~g} ; \mathrm{MgCl}_{2} \cdot 6 \mathrm{H}_{2} \mathrm{O}, 5 \mathrm{~g} ; \mathrm{MgSO}_{4} \cdot 7 \mathrm{H}_{2} \mathrm{O}, 0.25 \mathrm{~g}$; $\mathrm{KCl}$, $0.2 \mathrm{~g}$; $\left(\mathrm{NH}_{4}\right)_{2} \mathrm{SO}_{4}, 0.1 \mathrm{~g}$ and one rock phosphate at $5 \mathrm{~g} \mathrm{~L}^{-1}$, plus $0.5 \%$ BCG dye as previously described, $\mathrm{pH} 7.5$. After 5 days incubation at $28{ }^{\circ} \mathrm{C}$, the solubilisation index of each fungal strain was determined.

\subsection{Ability of Fungi to Solubilise Rock Phosphates in Liquid Culture}

Microorganisms were tested in liquid media to assess their capability in releasing phosphorus from insoluble sources; $50 \mathrm{ml}$ NBRIP medium were distributed into $250 \mathrm{ml}$ 
Erlenmeyer flasks, individual rock phosphate types (Malian RP, Moroccan RP, Algerian RP, or Mexican RP) was added to the medium at the concentration of $5 \mathrm{gL}^{-1}$ and the $\mathrm{pH}$ adjusted to 7.5. After sterilisation and cooling, $200 \mu \mathrm{l}$ mycelia suspensions were used to inoculate flasks containing the different rock phosphates in triplicate. Triplicate non-inoculated flasks supplemented with the different rock phosphates served as controls. Incubation was made at $28{ }^{\circ} \mathrm{C}, 150 \mathrm{rpm}$ for 7 days. Cultures were then transferred into sterile falcon tubes, centrifuged at 10000 rpm for 10 minutes and aliquots taken for both $\mathrm{P}$ and $\mathrm{pH}$ measurement.

\subsection{Identification of Fungal Strains}

Identification was made from pure isolates diluted and pre heated at $95^{\circ} \mathrm{C}$ for 10 minutes. Amplification of $18 \mathrm{~S}$ rRNA gene was performed from the genomic DNA of strains. Fungal PCR cocktails $(24 \mu \mathrm{l})$ contained Water $(18.1 \mu \mathrm{l})$, Buffer $(2.6 \mu \mathrm{l}), 817 \mathrm{~F}(0.5 \mu \mathrm{l}), 1536 \mathrm{R}(0.5 \mu \mathrm{l}), \mathrm{MgSO}_{4}(1 \mu \mathrm{l})$, dNTPs $(0.5 \mu \mathrm{l})$, BSA $(0.5 \mu \mathrm{l})$, Platinum Taq $(0.1 \mu \mathrm{l})$ and HhaI $(0.2 \mu \mathrm{l})$. Possible contamination with microbial template was minimised through pre digestion of components with hha I. One microliter of the preheated fungal cells was added to the predigested Master mix and the amplification was performed in a DNA thermo cycler at $94{ }^{\circ} \mathrm{C}$ for 4.5 minutes followed by 30 cycles of 30 seconds at $94{ }^{\circ} \mathrm{C}$ denaturation, 30 seconds at $55^{\circ} \mathrm{C}$ annealing and 1.5 minute at $68^{\circ} \mathrm{C}$ with final extension of $68^{\circ} \mathrm{C}$ for 10 minutes. A $3 \mu \mathrm{l}$ aliquot of each amplification product was electrophoresed on a $1 \%$ agarose gel in $1 \times$ TAE buffer at 50 $\mathrm{V}$ for $30 \mathrm{~min}$ and the PCR products were visualised with a $\mathrm{UV}$ transilluminator. PCR products adjusted to $25-30 \mathrm{ng} / \mu \mathrm{l}$ were sequenced with automated DNA sequencer with specific primers, either $817 \mathrm{~F}$ or $1536 \mathrm{R}$. The sequences were edited and compared with $18 \mathrm{~S}$ sequences on the GenBank, using the algorithm BLASTN-NCBI in order to find the homologous sequences.

Table 2. Sequence of the different strains.

\begin{tabular}{|c|c|}
\hline Strains & Sequences \\
\hline Penicillium sp. 27 & $\begin{array}{l}\text { AGGGATAGTCGGGGGCGTCAGTATTCAGCTGTCAGAGGTGAAATTCTTGG } \\
\text { ATTTGCTGAAGACTAACTACTGCGAAAGCATTCGCCAAGGATGTTTTCAT } \\
\text { TAATCAGGGAACGAAAGTTAGGGGATCGAAGACGATCAGATACCGTCGTA } \\
\text { GTCTTAACCATAAACTATGCCGACTAGGGATCGGACGGGCTTCTATGATG } \\
\text { ACCCGTTCGGCACCTTACGAGAAATCAAAGTTTTTGGGTTCTGGGGGGAG } \\
\text { TATGGTCGCAAGGCTGAAACTTAAAGAAATTGACGGAAGGGCACCACAAG } \\
\text { GCGTGGAGCCTGCGGCTTAATTTGACTCAACACGGGGAAACTCACCAGGT } \\
\text { CCAGACAAAATAAGGATTGACAGATTGAGAGCTCTTTCTTGATCTTTTGG } \\
\text { ATGGTGGTGCATGGCCGTTCTTAGTTGGTGGAGTGATTTGTCTGCTTAAT } \\
\text { TGCGATAACGAACGAGACCTCGGCCCTTAAATAGCCCGACCCGCTTTTGC } \\
\text { GGGCCGCTGGCTTCTTAGGGGGACTATCGGCTCAAGCCGATGGAAGTGCG } \\
\text { CGGCAATAACAGGTCTGTGATGCCCTTAGATGTTCTGGGCCGCACGCGCG } \\
\text { CTACACTGACAGGGTCAGCGAGTACATCACCTTGGCCGAGAGGTCTG. }\end{array}$ \\
\hline Penicillium sp. 43 & $\begin{array}{l}\text { GACGCCGTATGATAATAGGGATAGTCGGGGGCGTCAGTATTCAGCTGTCA } \\
\text { GAGGTGAAATTCTTGGATTTGCTGAAGACTAACTACTGCGAAAGCATTCG } \\
\text { CCAAGGATGTTTTCATTAATCAGGGAACGAAAGTTAGGGGATCGAAGACG } \\
\text { ATCAGATACCGTCGTAGTCTTAACCATAAACTATGCCGACTAGGGATCGG }\end{array}$ \\
\hline
\end{tabular}

\subsection{Statistical Analysis}

Statistical analyses were performed with Sigma plot 12.0. The analysis of variance (ANOVA) was run to find difference between factors and the HSD Turkey test to compare the different treatments. The correlation within the solved $\mathrm{P}$ and $\mathrm{pH}$ of the corresponding media were assessed using Statistica 9.

\section{Results}

\subsection{Identification of Strains}

The three Penicillium species were respectively labelled Ber-fm $F_{1}$, isolated on farm field in agro ecological zone V, with 27 as strain number; Wak-fm $\mathrm{F}_{2}$ isolated on farm field in agro ecological zone II, with 43 as strain number and Dsc- $\mathrm{ft} \mathrm{F}_{5}$ isolated on forest field in agro ecological zone III, with 109 as strain number. The sequences of the different strains are indicated in Table 2 . .

\subsection{Strains Characterization on Plates Supplemented with Sparingly Soluble Inorganic and Organic Phosphates}

The solubilisation index which equals to 1 indicates the non solubilisation ability by the fungal strains while the rating indicates the phosphate type that was solubilised by each strain (Table 3). P.27 was the strain able to show halo zone on plates amended with the different $\mathrm{P}$ types, while the strain P.109 was able to solubilise Ca-P and Al-P only. The highest SI was performed by P.27 on plates supplemented with Ca-P (2.43) and Na-phy (1.45), that strain being the only one able to show halo zone on plate amended with Fe-P. Al-P (4.74). An example of halo zone displayed by P.27 on plates amended with the different phosphate types is shown in Figure 1. However, the strain P. 109 shows the highest SI on plate with 


\begin{tabular}{ll}
\hline Strains & Sequences \\
\hline GCGGGGTTTCTATGATGACCCGCTCGGCACCTTACGAGAAATCAAAGTTT \\
TTGGGTTCTGGGGGGAGTATGTCGCAAGGCTGAAACTTAAAGAAATTGA \\
CGGAAGGGCACCACAAGGCGTGGAGCCTGCGGCTTAATTTACTCAACAC \\
GGGGAAACTCACCAGGTCCAGACAAAATAAGGATTGACAGATTGAGAGCT \\
CTTTCTTGATCTTTTGGATGGTGGTGCATGGCCGTTCTTAGTTGGTGGAG \\
TGATTTGCTGCTTAATTGGATAACGAACGAGACCTCGGCCCTAAATA \\
GCCCGGTCCGCGTTTGCGGGCCGCTGGCTTCTTAGGGGGACTATCGGCTC \\
AAGCCGATGGAAGTACGTGGCAATAACAGGTCTGTGATGCCCTTAGATGT \\
TCTGGGCCGCACGCGCGCTACACTGACAGGGTCAGCGAGTACATCACCTT \\
GGCCGAGAGGTCTGGGTAATCTTGTTACACCCTGTCGTGCTGGG. \\
\hline TAGGGATAGTCGGGGGCGTCAGTATTCAGCTGTCAGAGGTGAAATTCTTG \\
GATTTGCTGAAGACTAACTACTGCGAAAGCATTCGCCAAGGATGTTTCA \\
TTAATCAGGGAACGAAAGTTAGGGGATCGAAGACGATCAGATACCGTCGT \\
AGTCTTAACCATAAACTATGCCGACTAGGGATCGGACGGGCTTCTATGAT \\
GACCCGTTCGGCACCTTACGAGAAATCAAAGTTTTGGGTTCTGGGGGGA \\
GTATGGTCGCAAGGCTGAAACTTAAAGAAATTGACGGAAGGGCACCACAA \\
GGCGTGGAGCCTGCGGCTTAATTGACTCGACACGGGGAAACTCACCAGG \\
TCCAGACAACATAAGGATTGACAGATTGAGAGCTCTTTCTTGATCTTTTG \\
GATGGAGGTGCATGGCCGTTCTTAGATGGAGGAGTGATTTGTCTGCTTAA \\
TTGCGATAACGAACGAGACCTCGGCCCTTAAATAGACCGACCCGCTTTTG \\
CGGGCCGCTGGCTTCTTATGGGGACTATCGGCTCAAGCCGATGGAAGTGC \\
GCGGCAATAACAGGTCTGTGATGCCCTTATATGTTCTGGGCCGCACGCGC \\
GCTACACT. \\
\hline
\end{tabular}

Table 3. Solubilisation Index of strains on plates supplemented with sparingly soluble inorganic and organic phosphates.

\begin{tabular}{cccccc}
\hline Strains & $\begin{array}{c}\text { (a) } \mathrm{MM} \\
\text { with } \\
\mathrm{Ca}_{3}\left(\mathrm{PO}_{4}\right)\end{array}$ & $\begin{array}{c}\text { (b) } \mathrm{MM} \\
\text { with } \\
\mathrm{AlPO}_{4}\end{array}$ & $\begin{array}{c}\text { (c) } \mathrm{MM} \\
\text { with } \\
\mathrm{FePO}_{4}\end{array}$ & $\begin{array}{c}\text { (d) } \mathrm{MM} \\
\text { with } \\
\text { Na-Phyt } \\
\text { ate }\end{array}$ & Rating \\
\hline $\begin{array}{c}\text { Penicillium } \\
\text { sp. 27 }\end{array}$ & 2.43 & 3.92 & 1.43 & 1.45 & a,b,c,d \\
$\begin{array}{c}\text { Penicillium } \\
\text { sp. 43 }\end{array}$ & 2.29 & 3.89 & 1.00 & 1.44 & a,b,d \\
$\begin{array}{c}\text { Penicillium } \\
\text { sp. 109 }\end{array}$ & 1.64 & 4.74 & 1.00 & 1.00 & $\mathrm{a}, \mathrm{b}$ \\
\hline
\end{tabular}

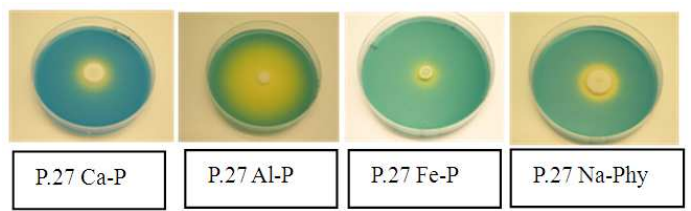

Figure 1. Halo (yellow) zone displayed by P.27 on plates amended with the different sparingly soluble phosphates. The yellow colour indicates the drop of $\mathrm{pH}$ of the medium associated to the process of P solubilisation..

\subsection{Strains Characterization on Plates Supplemented with Rock Phosphates of Different Origins}

\subsubsection{Solubilisation Index of Strains}

The solubilisation index was equally used here to evaluate the efficiency of strains in solubilising rock phosphate of different origins on plates. All the strains were able to solubilise Malian and Algerian rock phosphates (Figure 2), with the highest index displayed by strain P.109 on both Malian and Algerian rock phosphates. However, none of the strains was able to show any visible halo zone on plate amended with Moroccan rock phosphate $(\mathrm{SI}=1)$. An example of halo zone (Figure 3 ) displayed by the different strains on plate supplemented with Algerian rock phosphate can be observed.

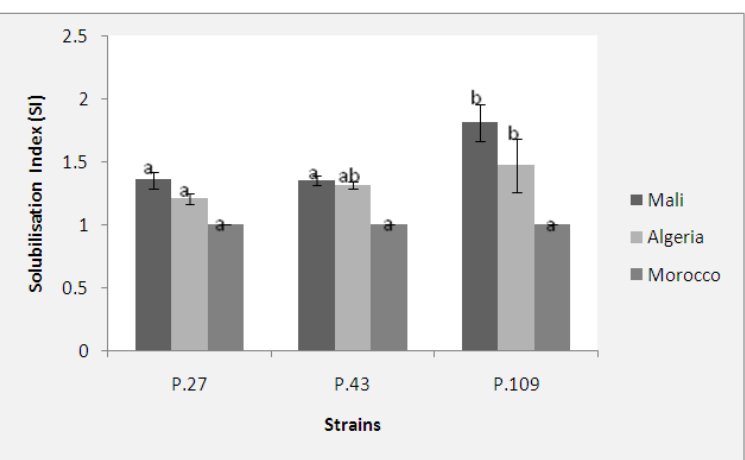

Figure 2. Solubilisation index of strains on plates supplemented with rock phosphates of different origins. The different letters within the same phosphate type are significantly different $(p<0.05)$.

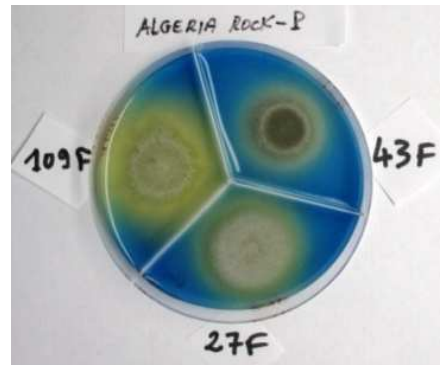

Figure 3. Halo (yellow) zone displayed by the different strains on plate supplemented with Algeria rock phosphate. The yellow colour indicates the drop of $\mathrm{pH}$ associated to the process of phosphate solubilisation. 


\subsubsection{Efficiency of Strains according to their SI}

According to figure 4, the strain P.109 appears to be the most efficient on plate, independently to phosphate type, while strains P.27 and P.43 displayed the equal aptitude.

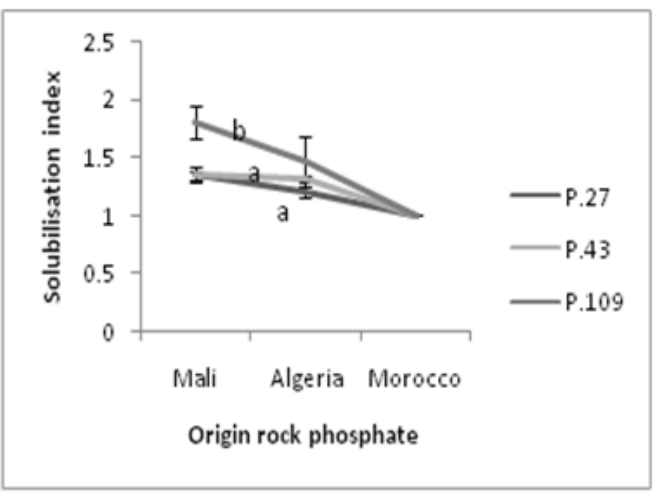

Figure 4. Aptitude of strains in solubilising rock phosphates of different origins on plates. The different letters indicate a significant difference between strains regardless the phosphate type.

\subsubsection{Fluency of the Different Rock Phosphate to be Solubilised on Plates}

The Malian rock phosphate appears the easiest to be solubilise on plate (Figure 5), followed by Algerian rock phosphate, while Moroccan rock phosphate seems to be the most recalcitrant on plate.

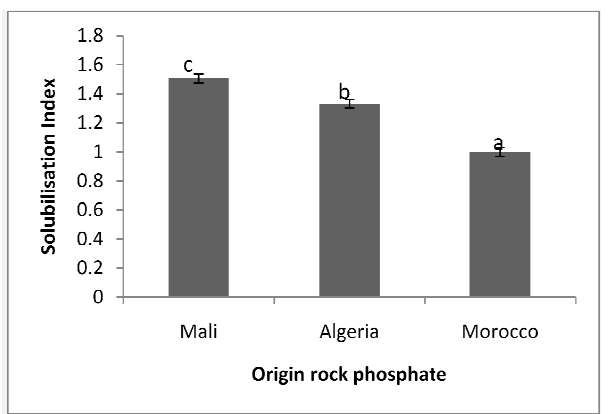

Figure 5. Fluency of the different rock phosphates to be solubilised by the strains on plates. The different letters indicate a significant difference between rock phosphates $(p<0.05)$.

\subsection{Strains Characterization in Liquid Cultures Supplemented with Rock Phosphates of Different Origins}

\subsubsection{Solved Phosphorus and $\mathrm{pH}$ in Liquid Cultures}

Important amount of phosphorus was mobilised from the insoluble rock phosphate sources (Figure 6a) by all the strains compared to the non-inoculated control. Significant differences $(\mathrm{p}<0.05)$ are observed within control and strains regarding all the phosphate types. The solubilisation of rock phosphate is associated to the $\mathrm{pH}$ decrease of the media amended with the different $\mathrm{P}$ types (Figure $6 \mathrm{~b}$ ). While the $\mathrm{pH}$ of control media is maintained at neutral, that of the inoculated media is almost acidic, and the acidity seems to be linked to the amount of the solved P for strains P.109 and P.27.

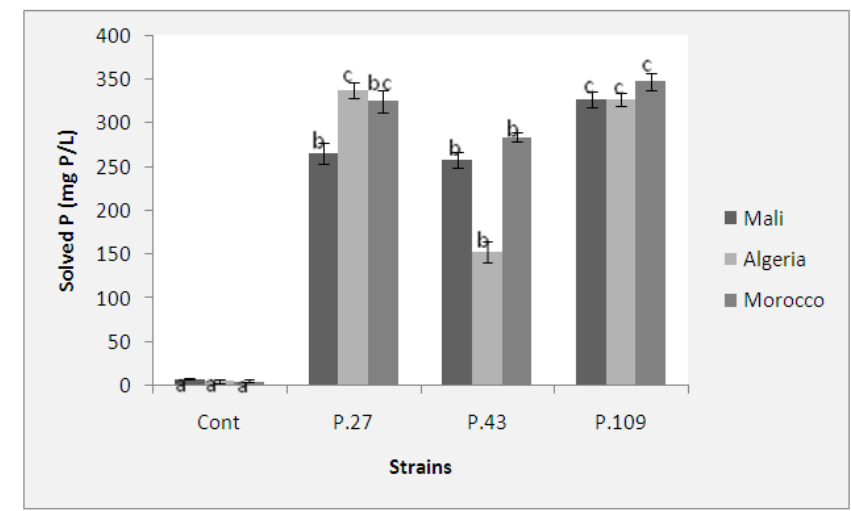

Figure 6a. Concentration of the solved $P$ in liquid cultures amended with rock phosphates of different origins. The different letters within the same phosphate type are significantly different $(p<0.05)$.

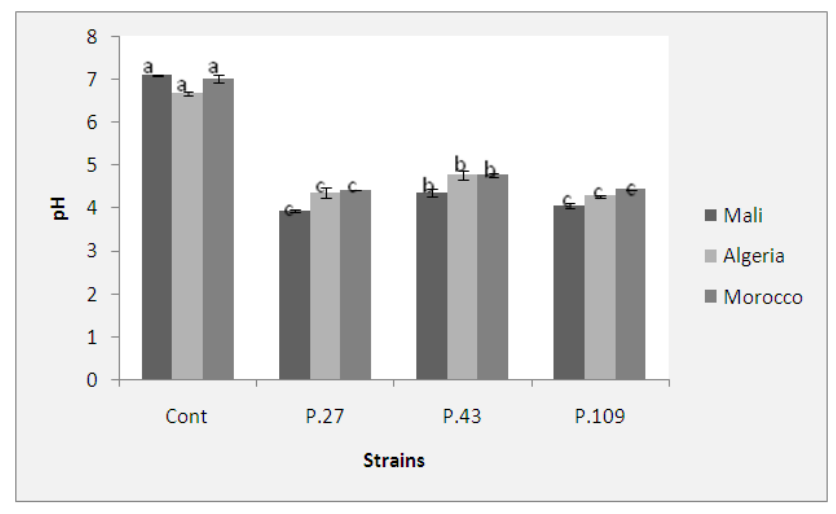

Figure 6b. $p H$ of the corresponding media after seven days of incubation. The different letters within the same phosphate type are significantly different $(p<0.05)$.

\subsubsection{Efficiency of Strains according to the concentration of the Solved $P$}

While significant amount of $\mathrm{P}$ are mobilised by all the strains compared to control, the highest amount is mobilised by strains P.109 and P.27 (Figure 7). Nevertheless, P.43 shows high performance regarding Malian and Moroccan rock phosphates, but with low activity on Algerian rock phosphate.

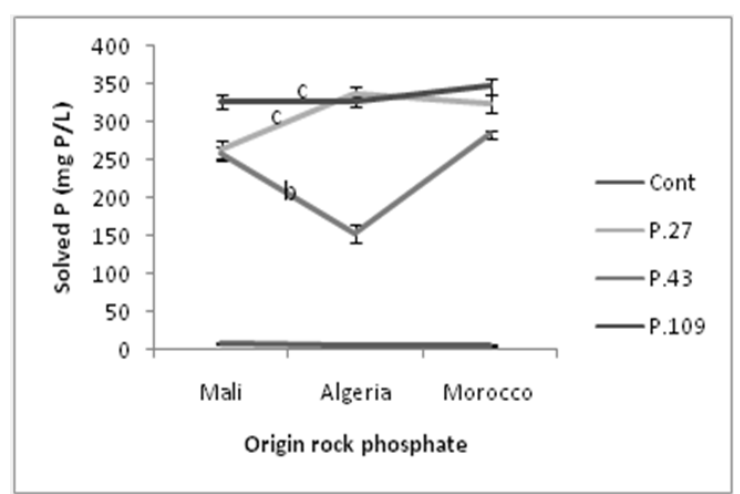

Figure 7. Aptitude of strains in solubilising rock phosphates of different origins in liquid media. The different letters indicate a significant difference between strains regardless the phosphate type $(p<0.05)$. 


\subsubsection{Fluency of the Different Rock Phosphate to be Solubilised in Liquid Media}

Contrary to the results obtained on plates, the Moroccan rock phosphate seems to be easily mobilised by strains in liquid medium, compared to Malian and Algerian rock phosphates (Figure 8). So, all the strains that did not show any halo zone on plates amended with the Moroccan rock phosphate were able to mobilise significant amounts in liquid media containing the same rock phosphate type.

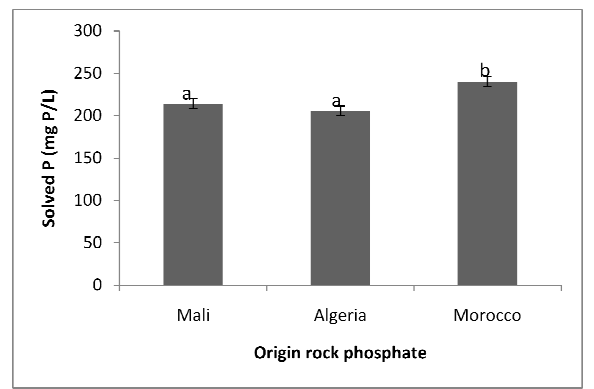

Figure 8. Facility of the different rock phosphates to be solubilised by the strains in liquid media. The different letters indicate a significant difference between rock phosphates $(p<0.05)$

\subsection{Correlation between Concentration of the Solved $P$ and the pH of the Corresponding Media}

Strong correlation was observed within the solved $\mathrm{P}$ and the corresponding media. Here, higher the amount of the solved $\mathrm{P}$, lower is the $\mathrm{pH}$ of the corresponding media.

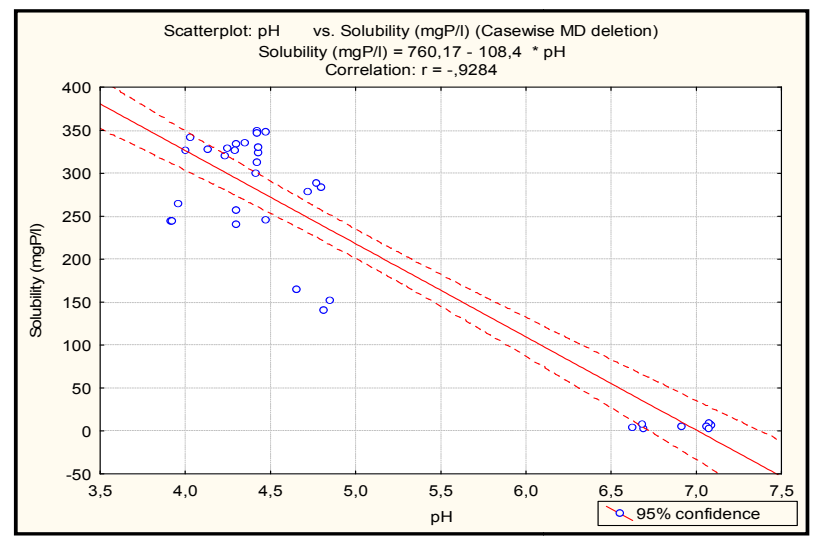

Figure 8. Correlation between $\mathrm{pH}$ and the solved $\mathrm{P}$ at the end of the incubation time $(p<0.05)$.

\section{Discussion}

The first phosphate solubilising activity of the strains was assessed on agar plates containing sparingly soluble inorganic phosphates (Ca-P, Al-P, Fe-P), one organic phosphate (Na-phy) as well as rock phosphate plus dye for better observation $[9,12,13]$. This reaction, shown as a halo or clear or yellow (in the present case) zone on the plate is used to assess the P solubilisation activity of strains [14], with the SI value as an indicator for the strain efficiency. Thus, the higher the SI value, the greater is the activity of the tested strain. The yellow colour associated to the strain activity indicates the drop of $\mathrm{pH}$ at this place, related to the change of the dye (Bromocresol green), moving from green (pH greater than 6) to yellow (pH ranging from 5.4 to 3.8). The strains were considered as phosphate solubilisers (PS) or rock phosphate solubilisers while solubilising at least one of the inorganic/organic phosphate types and one rock phosphate. Some Penicillium species have been characterized for their inorganic and organic phosphate solubilisation as well as rock phosphate solubilisation ability. These include Penicillum rugulosum [15,16]; P. oxalicum [9], P. Bilaiae, P.simplicissimum and P. minioluteum [17]. Although P.109 was not able to solubilise sparingly soluble Fe-P and Na-phy on plate, it appears the best rock phosphate solubiliser on plate, independently to rock phosphate origin. While comparing the relative efficiency of strains using the different RP, it was observed that RP solubilisation depended on the nature of RP and the organism, and the relative efficiency of strains for RP solubilisation may have been due to the nature and quantity of organic acids secreted in the medium [8]. Overall, fungi showed better solubilisation of all the rock phosphates. However, the degree of phosphate solubilisation varied with the type of organisms involved as well as the rock phosphate origin. None of the strains showed any halo zone on plates amended with Moroccan rock phosphate. They conversely mobilised an important amount of $\mathrm{P}$ in liquid culture supplemented with the same rock phosphate. These contradictory results between plate halo detection and phosphate solubilization in liquid cultures were found by Fankem et al. [13] and Deubel and Merbach [18]. This indicates that liquid culture should be associated to halo zone for rock phosphate solubilisers characterization [4]. However, while screening a large number of microorganisms, the halo detection method can be regarded as generally reliable for isolation and preliminary characterization of rock phosphate-solubilising microorganisms. In agreement with the present findings, two fungal strains, Penicillium bilaii and $P$. cf. fuscum were found to solubilise relative amounts of rock phosphates in liquid culture [19], and the inorganic $\mathrm{P}$ as well as the rock phosphate solubilisation were directly related to the $\mathrm{pH}$ drop generated by each strains [20]. In the present study, a strong correlation could be established between the quantity of phosphate solubilised and drop in $\mathrm{pH}$. This is not in agreement with the findings of Narsian and Patel [8], but could be explained by the significant positive correlation observed by Babana et al. [4] between the solved P and organic acids produced by PSM, suggesting that organic acids may play an important role although it is not the only possible mechanism for $\mathrm{P}$ solubilisation. As rock phosphates are theoretically the cheapest fertilizers but with low P availability, the assessment of the three Penicillium strains as rock phosphate solubilisers, is important as rock phosphate can be directly applied to soil and their solubilisation optimized by these strains. This agrees with view of Yu et al. [21], Silva and Vidor [22] who investigated the solubilization of rock phosphate in liquid culture by Aspergillus niger and Penicillium oxalicum. However, more work is required regarding the nature of rock 
phosphates and their interaction with efficient PSM.

\section{Conclusion}

The results obtained on agar plates and in liquid media amended with either sparingly soluble phosphates or rock phosphates showed the real aptitude of the three Penicillium strains in mobilising important amounts of phosphorus from insoluble phosphate sources. The efficiency of strains was assessed on plates through the solubilisation index that is a quick way to characterize and select strains for their phosphate solubilising activity. Liquid culture experiment involved the $\mathrm{P}$ measurement as well as the $\mathrm{pH}$ of the corresponding media. All the three strains were capable to mobilise important amount of phosphorus from the insoluble rock phosphate sources, and the $\mathrm{pH}$ of the corresponding media were correlated to the amount of the solved P. These strains can be used for the solubilisation of fixed phosphates into the agricultural soil systems. However, the selection of phosphate solubilising Penicillium strains as possible inoculation tools for phosphate-deficient soils should focus on the integral interpretation of laboratory assays, greenhouse experiments as well as field trials.

\section{Acknowledgments}

The authors would like to thank the Rothamsted International, African Fellow Programme, London, UK for providing the fund and the James Hutton Institute, Dundee, Scotland where part of this work was done.

\section{References}

[1] S.S.S. Rajan, J.H. Watkinson, A.G. Sinclair, Phosphate rocks for direct application to soils, vol. 57. Adv. Agron. 1996, pp. $77-159$.

[2] H.T. Rogers, R.W. Pearson, L.E. Ensminger, Comparative efficiency of various phosphate fertilizers, vol. 4. Agronomy, 1953, pp. 189-242.

[3] G.W. Cooke, The value of rock phosphate for direct application, vol. 24. Empire Journal of Experimental Agriculture 1956, pp. 295-306.

[4] A.H. Babana, A. H. Dicko, K. Maïga and D. Traoré, Characterization of rock phosphate-solubilizing microorganisms isolated from wheat (Triticum aestivum L.) rhizosphere in Mali, vol. 1(1). Journal of Microbiology and Microbial Research 2013, pp. 1-6.

[5] A.C. Gaur, \& K.P. Ostwall, Infuence of phosphate dissolving bacilli on yield and phosphate uptake of wheat crop, vol. 10 . Indian Journal of Experimental Biology 1972, pp. 393-394.

[6] A.H. Babana, H. Antoun, Effect of Tilemsi phosphate rock solubilizing microorganisms on phosphorus-uptake and yield of field grown wheat in Mali, vol. 287. Plant and Soil, 2006, pp. 51-58.

[7] H. Hamdali, K. Moursalou, G. Tchangbedji, Y. Ouhdouch, H. Mohamed, Isolation and characterization of rock phosphate solubilizing actinobacteria from a Togolese phosphate mine, vol. 11(2). Afr. J. Biotechnol. 2012, pp. 312-320.

[8] Varsha Narsian, H.H. Patel, Aspergillus aculeatus as a rock phosphate solubilizer, vol. 32. Soil Biology \& Biochemistry, 2000, pp. 559-565.

[9] R.S. Gadagi, T. Sa, New Isolation Method for Microorganisms Solubilizing Iron and Aluminium Phosphates Using Dyes, vol. 48(4). Soil Science and Plant Nutrition, 2002, pp. 615-618.

[10] M.A. Qureshi, Z.A. Ahmad, N. Akhtar, A. Iqbal, F. Mujeeb, M.A. Shakir, Role of phosphate solubilizing bacteria (PSB) in enhancing $P$ availability and promoting cotton growth, vol. 22. The journal of animal \& plant sciences, 2012, pp. 204-210.

[11] C.S. Nautiyal, An efficient microbiological growth medium for screening phosphate solubilizing microorganisms, vol. 170. FEMS Microbiology Letters, 1999, pp. 265-270.

[12] S. Mehta, S.C. Nautiyal, An efficient method for qualitative screening of phosphate-solubilizing bacteria, vol. 43. Current Microbiol., 2001, pp. 51-56.

[13] H. Fankem, M. Abba, L. Ngo Nkot, A. Deubel, W. Merbach, F.X. Etoa and D. Nwaga, "Selecting indigenous $P$ solubilizing bacteria for cowpea and millet improvement in nutrient deficient acidic soils of southern Cameroon". In Innovations for a green revolution in Africa: Exploring the Scientific Facts. A. Bationo, B. Waswa, J. Okeyo, F. Maina (Eds.). Springer Science+Business Media B.V. 2011 (DOI 10.1007/978-90-481-2543-2_40), pp. 391-398.

[14] L.A. Fernandez, P. Zalba, M.A. Gomez, M.A. Sagardoy, Phosphate solubilization activity of bacterial strains in soil and their effect on soybean growth under greenhouse conditions, vol. 43. Biol. Fert. Soils, 2007, pp. 805-809.

[15] Reyes, R. Baziramakenga, L. Bernier, and H. Antoun, Solubilization of phosphate rocks and minerals by a wild-type strain and two UV-induced mutants of Penicillium rugulosum, vol. 33. Soil Biology and Biochemistry, 2001, pp. 1741-1747.

[16] Reyes, L. Bernier, H. Antoun, Rock phosphate solubilization and colonization of maize rhizosphere by wild and genetically modified strains of Penicillum rigulosum, vol. 44 . Microbial Ecology, 2002, pp. 39-48.

[17] S.A. Wakelin, R.A. Warren, P.R. Harvey, M.H. Ryder, Phosphate solubilization by Penicillium spp. closely associated with wheat roots, vol. 40. Biology and Fertility of Soils, 2004, pp. 36-43.

[18] A. Deubel, W. Merbach, "Influence of microorganisms on phosphorus bioavailability in soils". In Microorganisms in soils: roles in genesis and functions. F. Buscot, A. Varma (eds). Springer, Berlin Heidelberg, 2005, pp. 177-191.

[19] P.E.A. Asea, R.M.N. Kucey, J.W.B. Stewart, Inorganic phosphate solubilization by two Penicillium species in solution culture and in soil, vol. 20. Soil Biology \& Biochemistry, 1988, pp. 459-464.

[20] S.A. Omar, The role of rock-phosphate-solubilizing fungi and vesicular-arbusular-mycorrhiza (VAM) in growth of wheat plants fertilized with rock phosphate vol. 14. World Journal of Microbiology \& Biotechnology, 1988, pp. 211-218. 
[21] S.L. Yu, Y.N. Liu, G.L. Jing, B.J. Zhao, S.Y. Guo, Analysis of phosphate-accumulating organisms cultivated under different carbon sources with polymerase reaction-denaturing gradient gel electrophoresis assay, vol. 17. J. Environ. Sci., 2005, pp. 611-614.
[22] G.N. Silva, C. Vidor, Phosphate solubilising activity of microorganisms in the presence of nitrogen, iron, calcium and potassium, vol. 36. Pestic Agro Bras., 2001, pp. 1495-1508 